\title{
Circulating cell-free DNA as a prognostic and predictive biomarker in non-small cell lung cancer
}

\author{
Bo Ai ${ }^{1}$, Huiquan Liu ${ }^{2}$, Yu Huang ${ }^{2}$, Ping Peng ${ }^{2}$ \\ ${ }^{1}$ Department of Thoracic Surgery, Tongji Hospital, Tongji Medical College, Huazhong University of Science and Technology, \\ Hubei, Wuhan 430030, People's Republic of China \\ ${ }^{2}$ Department of Oncology, Tongji Hospital, Tongji Medical College, Huazhong University of Science and Technology, Hubei, \\ Wuhan 430030, People's Republic of China
}

Correspondence to: Ping Peng, email: pengpingtjh@163.com

Keywords: circulating cell-free DNA, non-small cell lung cancer, prognosis, biomarker, meta-analysis

Received: February 28, 2016

Accepted: May 29, 2016

Published: June 15, 2016

\section{ABSTRACT}

Circulating cell-free DNA (cfDNA), which can be obtained from plasma or serum by non-invasive procedures, has showed great potential to predict treatment response and survival for cancer patients. Several studies have assessed the prognostic and predictive value of cfDNA in non-small cell lung cancer (NSCLC). However, these studies were often small and reported varying results. To address this issue, a meta-analysis was carried out. A total of 22 studies involving 2518 patients were subjected to the final analysis. Our results indicated that NSCLC patients with higher cfDNA concentration had shorter median progression-free survival (PFS) and overall survival (OS) time. In addition, high levels of cfDNA were significantly associated with poor PFS (hazard ratio or HR, 1.32; 95\% CI, 1.02-1.71) and OS (HR, 1.64; 95\% CI, 1.26-2.15). With respect to tumor specific mutations, we failed to reveal significant differences for PFS (HR, 1.30; 95\% CI, 0.66-2.56) and OS (HR, 1.05; 95\% CI, 0.492.25) when NSCLC patients were grouped according to KRAS genotype detected in cfDNA. However, NSCLC patients which harbored EGFR activating mutation in cfDNA had a greater chance of response to EGFR-TKIs (odds ratio or OR, 1.96; 95\% CI, 1.59-2.42). No significant publication bias was detected in this study. In conclusion, cfDNA could act as a prognostic and predictive biomarker for patients with NSCLC.

\section{INTRODUCTION}

Lung cancer is the most commonly diagnosed cancer as well as the leading cause of cancer-related deaths in the world [1]. Non-small cell lung cancer (NSCLC) accounts for approximately $80 \%$ cases of lung cancer [2]. Most NSCLC patients are diagnosed with advanced or distant stages and they are ineligible for curative surgery and often suffer a poor survival. Identifying biomarkers related to treatment response and prognosis may be helpful to improve the clinical outcome of patients with NSCLC.

Circulating cell-free DNA (cfDNA), which can be isolated from the plasma or serum by non-invasive procedures, has been proposed as an attractive biomarker to estimate treatment response, detect drug resistance and predict clinical outcome for cancer patients [3-7]. It has been experimentally evidenced that tumor cells can release genomic DNA into the blood and circulating
DNA can reflect the tumor burden and tumor biologic characteristics $[6,8]$. A series of studies have shown that NSCLC patients have higher levels of cfDNA in the blood compared with healthy controls or patients with benign diseases [9-11]. The quantitative assay of cfDNA may be a screening tool for NSCLC. It has been shown that the diagnostic accuracy of quantitative analysis of cfDNA is not lower than conventional serum biomarkers for lung cancer screening [12]. Furthermore, cancer-associated genetic alterations, such as point mutations, deletions, and copy number variations, can be detected in cfDNA [13]. In NSCLC, many studies have investigated the diagnostic accuracy of cfDNA for detecting epithermal growth factor receptor $(E G F R)$ mutation [14-16]. Two recent metaanalyses demonstrated that cfDNA was a highly specific and effective biomarker to measure EGFR mutation status in NSCLC $[17,18]$. These evidences suggested that genotype in cfDNA could be a promising tumor biomarker for NSCLC. 
A large number of studies had investigated the predictive or prognostic value of cfDNA concentration in NSCLC patients in recent years [19-22] (see Table 1 for references). However, these studies were often small and reported varying results. Some of them showed that a higher cfDNA concentration was associated with poorer survival in NSCLC patients [19, 20], whereas other studies failed to demonstrate such correlation [21, 22]. On the other hand, several studies had analyzed the association between genotype detected in cfDNA with treatment response or survival in NSCLC [23-26]. Some of them suggested that tumor specific mutations such as $K R A S$ or $E G F R$ presented in cfDNA might be useful prognostic and predictive biomarkers for NSCLC $[23,24]$. However, some others indicated that such gene mutations in cfDNA had no predictive or prognostic value $[25,26]$.

As the existing studies are conflicting in their results, it is still difficult to determine the predictive and prognostic role of cfDNA in patients with NSCLC. Therefore, a meta-analysis aimed to address this issue was carried out.

\section{RESULTS}

\section{Search results}

Figure 1 illustrated the process of study selection. 298 studies were initially found by our search strategy. 30 articles were reviewed in detail after the article titles and abstracts were checked [9, 16, 19-46]. Eight studies were excluded from the meta-analysis [39-46], leaving 22 studies that fulfilled the eligibility criteria [9, 16, 1938] (Table 1). Among the 8 excluded studies, 7 did not provide sufficient data for extracting odds ratio (OR) or hazard ratio (HR) [39-45], and other 1 study was excluded because the same cohort of patients was used in other selected study [46]. The total number of patients included in this study was 2518 , ranging from 22 [21, 37] to 446 [29] cases per study. 12 studies evaluated the prognostic role of cfDNA concentration in NSCLC [9, 19-22, 27-33]. 4 studies reported the prognostic role of $K R A S$ genotype detected in cfDNA for NSCLC [20, 23, 25, 34]]. Another 7 studies dealt with the predictive role of EGFR genotype presented in cfDNA for NSCLC patients who were treated with tyrosine kinase inhibitors of EGFR (EGFR-TKIs) [16, 24, 26, 35-38].

\section{Impact of cfDNA concentration on the survival of NSCLC}

Six studies reported the median progression-free survival (PFS) time in NSCLC patients according to different cfDNA concentrations (high or low) [19, 20, 27, 29, 30, 32]. As showed in Figure 2A, patients with high levels of cfDNA usually had shorter PFS time than those with low cfDNA concentrations. In addition, the pooled
HR for PFS was 1.32 (95\% CI, 1.02-1.71; $P=0.038)$, suggesting that high cfDNA concentration was a good predictor of poor PFS (Figure 2B). For overall survival (OS), 6 of 7 studies reported shorter median OS times in NSCLC patients with higher cfDNA concentration (Figure 3A). Similar to the results of PFS, higher levels of cfDNA indicated lower overall survival rates with a pooled HR of 1.64 (95\% CI, 1.26-2.15; $P=0.000$ ) (Figure 3B). However, high heterogeneities were presented in these analyses $\left(I^{2}=73.6 \% ; P=0.000\right.$ for PFS; $I^{2}=75.5 \% ; P=$ 0.000 for OS).

As clinical stages and therapeutic regimens are correlated with patient's prognosis, they may bring heterogeneity to the overall analysis. Consequently, we focused on these two confounding variables in our subgroup analysis. As showed in Table 1, the majority of studies considered patients with advanced clinical stages (stage III-IV). Thus, we combined studies that focused on NSCLC patients with advanced stages to have a more homogenic group. The pooled HRs for PFS and OS were 1.29 (95\% CI, 1.02-1.65; $P=0.035 ; I^{2}=71.7 \%$; Figure 4A) and 1.64 (95\% CI, 1.19-2.25; $P=0.002 ; I^{2}=81.1 \%$; Figure 4B), respectively. We further performed another subgroup analysis according to the therapeutic regimens. As chemotherapy was the most commonly used treatment method in these studies, we then limited the analysis to studies considering patients treated with chemotherapy. The significant association could also be observed for both PFS (HR, 1.41; 95\% CI, 1.06-1.89; $P=0.020 ; I^{2}=76.0 \%$; Figure 5A) and OS (HR, 1.83; 95\% CI, 1.31-2.54; $P=$ $0.000 ; I^{2}=82.3 \%$; Figure $\left.5 \mathrm{~B}\right)$.

\section{Impact of $K R A S$ genotype detected in cfDNA on the survival of NSCLC}

The correlation between $K R A S$ genotype detected in cfDNA with survival in NSCLC patients was evaluated in four studies. The combined HR for PFS was 1.30 (95\% CI, 0.66-2.56; $P=0.450)$, suggesting that there were no significant differences between patients with $K R A S$ mutation and those with wild-type genotype with respect to PFS (Figure 6A). Moreover, our study failed to reveal significant difference for OS when NSCLC patients were grouped according to KRAS genotype detected in cfDNA (HR, $1.05 ; 95 \%$ CI, 0.49-2.25; $P=0.892$; Figure 6B). Thus, $K R A S$ genotype detected in cfDNA might not be a prognostic factor for survival in NSCLC patients.

\section{Impact of EGFR genotype detected in cfDNA on response to EGFR-TKIs}

Seven studies evaluated whether EGFR genotype detected in cfDNA could act as a predictor of response to EGFR-TKIs. As showed in Figure 7, the pooled OR for objective response rates (ORR) was 1.96 (95\% CI, 1.59$\left.2.42 ; P=0.000 ; I^{2}=71.4 \%\right)$. Our results suggested that 
Table 1: Characteristics of studies included in this meta-analysis

\begin{tabular}{|c|c|c|c|c|c|c|c|}
\hline First author & Country & No. & $\begin{array}{l}\text { Clinical } \\
\text { stage }\end{array}$ & $\begin{array}{l}\text { Therapeutic } \\
\text { regimen }\end{array}$ & $\begin{array}{l}\text { cfDNA } \\
\text { assessments }\end{array}$ & cfDNA analysis & Clinical factors \\
\hline Catarino $(2012)^{9}$ & Portugal & 104 & I-IV & chemotherapy & qPCR(hTERT) & quantification(H/L) & OS \\
\hline $\operatorname{Tissot}(2015)^{19}$ & France & 218 & III-IV & chemotherapy & $\begin{array}{l}\text { PicoGreen } \\
\text { dsDNA Kit }\end{array}$ & quantification(H/L) & PFS, OS \\
\hline & & & & & & quantification(H/L) & PFS, OS \\
\hline Nygaard $(2014)^{20}$ & Denmark & 58 & III-IV & chemotherapy & ARMS-qPCR & $\begin{array}{l}\text { KRAS } \\
\text { mutation(+/-) }\end{array}$ & PFS, OS \\
\hline Bortolin $(2015)^{21}$ & Italy & 22 & I & $\begin{array}{l}\text { stereotactic } \\
\text { body } \\
\text { radiotherapy }\end{array}$ & qPCR(hTERT) & quantification(H/L) & PFS, OS \\
\hline $\operatorname{Li}(2016)^{22}$ & America & 101 & III-IV & chemotherapy & $\mathrm{qPCR}(\beta$-Actin $)$ & quantification(H/L) & PFS, OS \\
\hline $\operatorname{Wang}(2014)^{27}$ & China & 134 & III-IV & EGFR-TKI & $\begin{array}{l}\text { ARMS/ } \\
\text { Scorpion assay }\end{array}$ & $\begin{array}{l}\text { quantification(H/L) } \\
E G F R \\
\text { mutation(+/-) }\end{array}$ & $\begin{array}{l}\text { PFS, OS } \\
\text { PFS, OS }\end{array}$ \\
\hline $\begin{array}{l}\text { Vinayanuwattikun } \\
(2013)^{28}\end{array}$ & Thailand & 58 & III-IV & chemotherapy & qPCR(GAPDH) & quantification(H/L) & OS \\
\hline $\operatorname{Sirera}(2011)^{29}$ & Spain & 446 & III-IV & chemotherapy & qPCR(hTERT) & quantification(H/L) & PFS, OS \\
\hline $\operatorname{Lee}(2011)^{30}$ & Korea & 134 & III-IV & $\begin{array}{l}\text { EGFR-TKI or } \\
\text { chemotherapy }\end{array}$ & $\mathrm{qPCR}(\beta$-Actin $)$ & quantification(H/L) & PFS, OS \\
\hline Ludovini $(2008)^{31}$ & Italy & 76 & I-III & $\begin{array}{l}\text { surgery+ } \\
\text { chemotherapy }\end{array}$ & qPCR(hTERT) & quantification(H/L) & PFS, OS \\
\hline Camps $(2006)^{32}$ & Spain & 99 & III-IV & chemotherapy & qPCR(hTERT) & quantification(H/L) & PFS, OS \\
\hline Gautschi $(2004)^{33}$ & Switzerland & 185 & I-IV & chemotherapy & $\begin{array}{l}\text { Fluorogenic } \\
\text { qPCR }\end{array}$ & quantification(H/L) & OS \\
\hline Nygaard $(2013)^{23}$ & Denmark & 246 & II-IV & chemotherapy & ARMS-qPCR & $\begin{array}{l}\text { KRAS } \\
\text { mutation(+/-) }\end{array}$ & PFS, OS \\
\hline Camps $(2005)^{25}$ & Spain & 67 & III-IV & chemotherapy & RFLP-PCR & $\begin{array}{l}\text { KRAS } \\
\text { mutation(+/-) }\end{array}$ & PFS, OS \\
\hline Gautschi $(2007)^{34}$ & Switzerland & 175 & I-IV & $\begin{array}{l}\text { surgery+ } \\
\text { chemotherapy }\end{array}$ & RFLP-PCR & $\begin{array}{l}\text { KRAS } \\
\text { mutation(+/-) }\end{array}$ & OS \\
\hline $\operatorname{Bai}(2009)^{16}$ & China & 102 & III-IV & EGFR-TKI & DHPLC & $\begin{array}{l}E G F R \\
\text { mutation(+/-) }\end{array}$ & ORR \\
\hline $\operatorname{Kimura}(2007)^{24}$ & Japan & 42 & III-IV & EGFR-TKI & $\begin{array}{l}\text { DNA } \\
\text { sequencing }\end{array}$ & $\begin{array}{l}E G F R \\
\text { mutation(+/-) }\end{array}$ & ORR \\
\hline Douillard $(2014)^{26}$ & Multicenter & 102 & III-IV & EGFR-TKI & $\begin{array}{l}\text { EGFR RGQ } \\
\text { PCR kit }\end{array}$ & $\begin{array}{l}E G F R \\
\text { mutation(+/-) }\end{array}$ & ORR \\
\hline $\operatorname{He}(2009)^{35}$ & China & 45 & I-IV & EGFR-TKI & $\begin{array}{l}\text { Mutant- } \\
\text { enriched PCR }\end{array}$ & $\begin{array}{l}E G F R \\
\text { mutation(+/-) }\end{array}$ & ORR \\
\hline
\end{tabular}




\begin{tabular}{|c|c|c|c|c|c|c|c|}
\hline First author & Country & No. & $\begin{array}{c}\text { Clinical } \\
\text { stage }\end{array}$ & $\begin{array}{l}\text { Therapeutic } \\
\text { regimen }\end{array}$ & $\begin{array}{l}\text { cfDNA } \\
\text { assessments }\end{array}$ & cfDNA analysis & Clinical factors \\
\hline $\operatorname{Kimura}(2006)^{36}$ & Japan & 27 & III-IV & EGFR-TKI & $\begin{array}{l}\text { DNA } \\
\text { sequencing }\end{array}$ & $\begin{array}{l}E G F R \\
\text { mutation(+/-) }\end{array}$ & ORR \\
\hline $\operatorname{Kim}(2013)^{37}$ & Korea & 22 & III-IV & EGFR-TKI & PNA-LNA PCR & $\begin{array}{l}E G F R \\
\text { mutation(+/-) }\end{array}$ & ORR \\
\hline $\operatorname{Li}(2014)^{38}$ & China & 55 & III-IV & EGFR-TKI & ARMS-qPCR & $\begin{array}{l}E G F R \\
\text { mutation(+/-) }\end{array}$ & ORR \\
\hline
\end{tabular}

Abbreviation: No., number; cfDNA, circulating cell-free DNA; qPCR, quantitative polymerase chain reaction; hTERT, human telomerase reverse transcriptase; ARMS, amplification refractory mutation system; GAPDH, glyceraldehydephosphate dehydrogenase; RFLP, restricted fragment length polymorphisms; DHPLC, denaturing high-performance liquid chromatography; PNA-LNA, peptide nucleic acid-locked nucleic acid; EGFR-TKI, epidermal growth factor receptortyrosine kinase inhibitor; H/L, high/low; +/-, mutation/wide-type; OS, overall survival; PFS, progression-free survival; ORR, objective response rate.

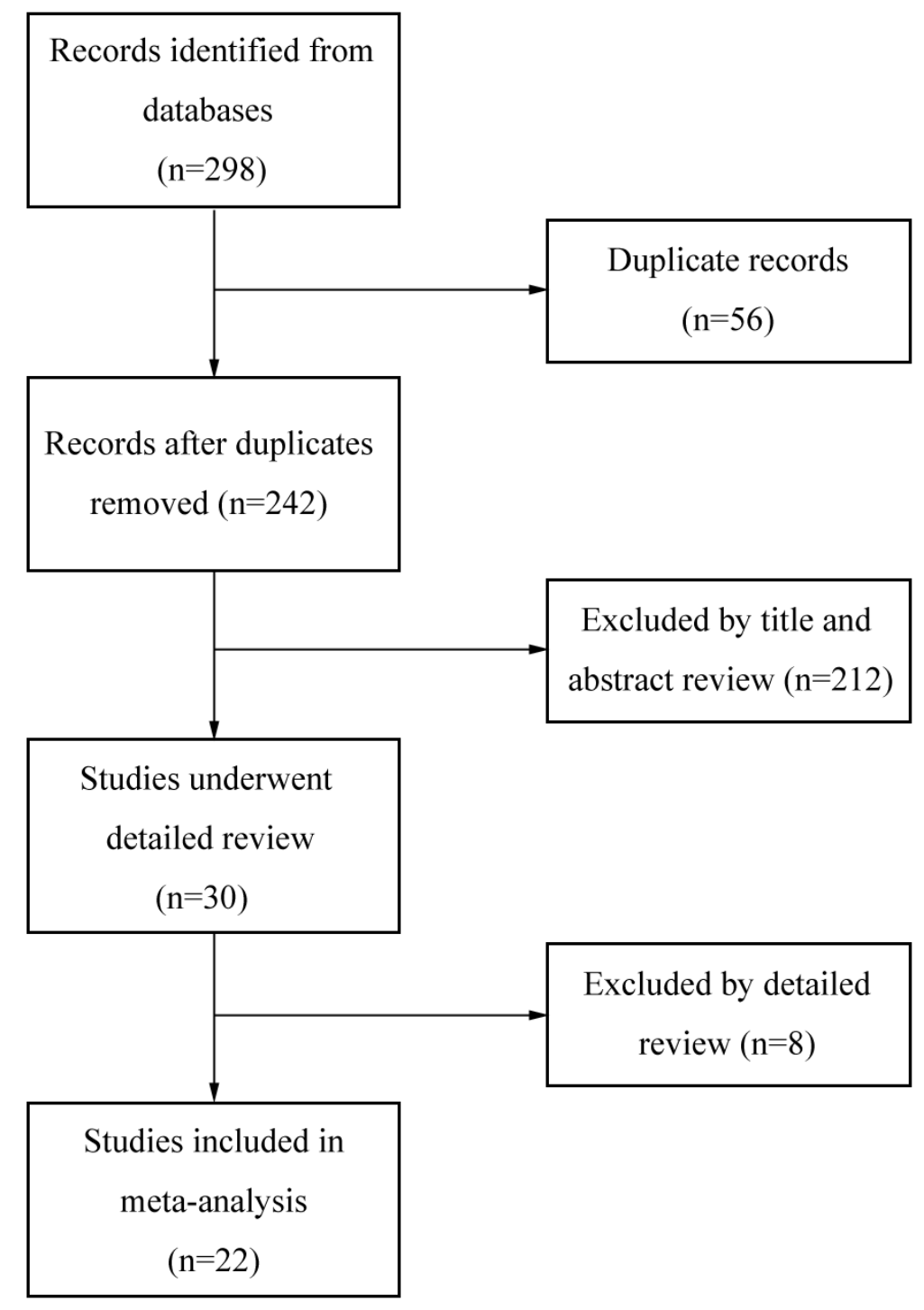

Figure 1: Flow diagram of study selection. 
patients with $E G F R$ activating mutation in cfDNA had a greater chance of response to EGFR-TKIs. Thus, EGFR genotype detected in cfDNA may be a good predictor of response to EGFR-TKIs for NSCLC patients.

\section{Publication bias}

We assessed the publication bias by visually assessing a funnel plot for asymmetry and by quantitatively performing Begg's test and Egger's test. As shown in Figure 8, there was no clear evidence of funnel plot asymmetry by visual assessment. Both Begg's test and Egger's test revealed that no publication bias was found when OS was analyzed (Begg's test, $\mathrm{p}=0.266$, Egger's test, $\mathrm{p}=0.286$ ). The Egger's test revealed a slight publication bias when PFS was analyzed (Begg's test, $\mathrm{p}=0.119$, Egger's test, $\mathrm{p}=0.035$ ). Thus, no significant publication bias existed in this study.

\section{DISCUSSION}

Non-invasive approaches, usually based on plasma or serum samples, have showed great potential for treatment monitoring in NSCLC patients [47]. cfDNA, as an easily acquired liquid biomarker and a potential surrogate for the entire tumor genome, may provide

A

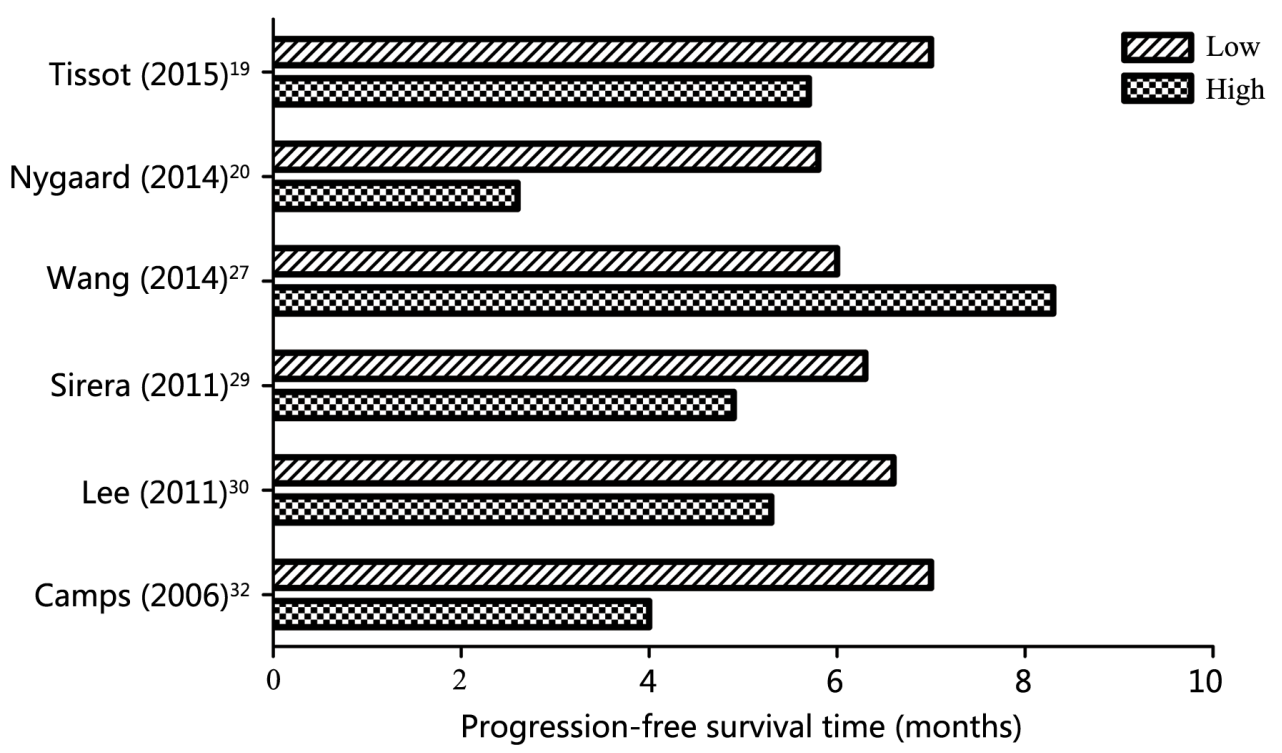

B

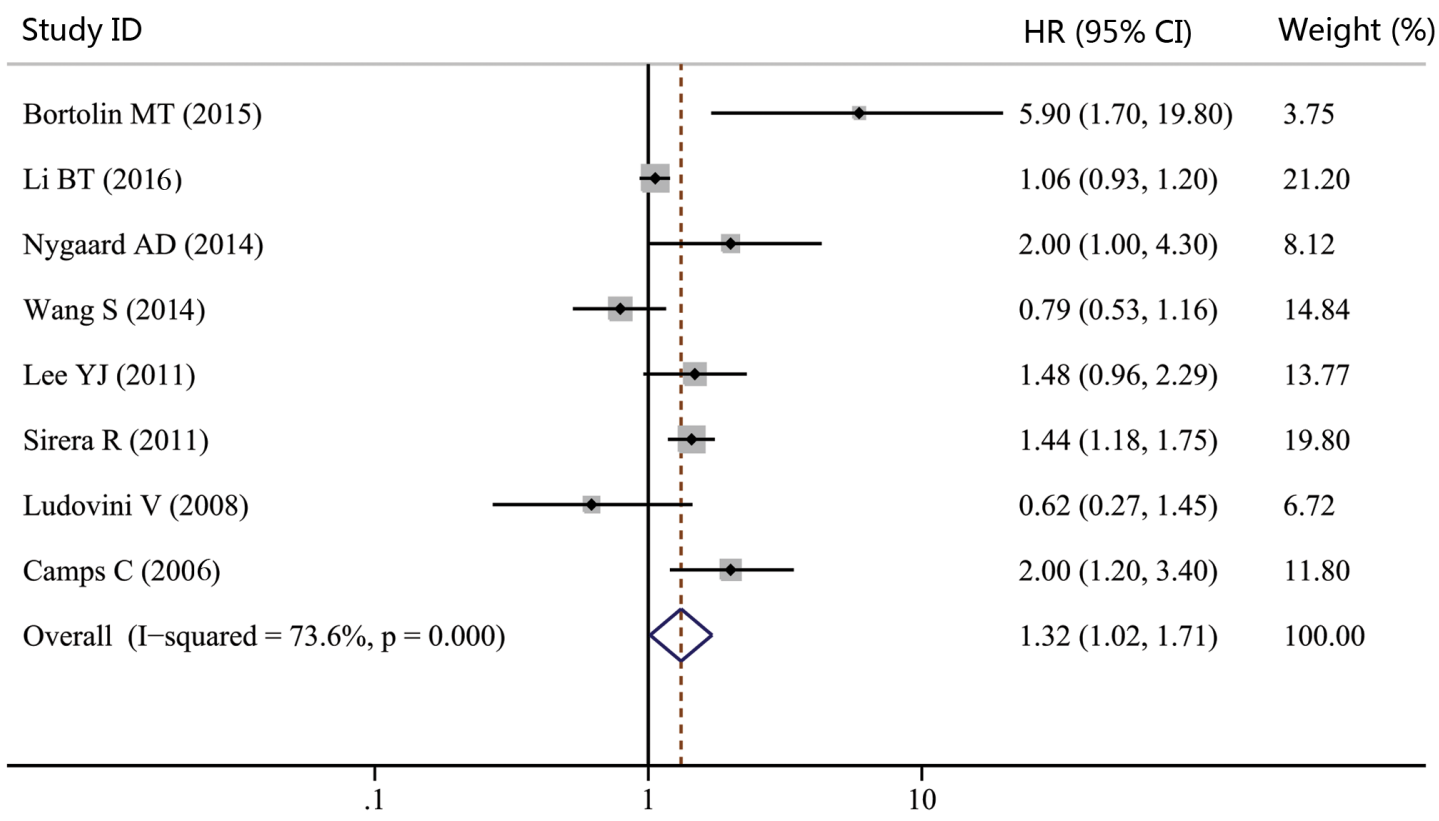

Figure 2: Progression-free survival (PFS) according to cfDNA concentration in NSCLC patients. A. Median PFS time according to cfDNA concentration. B. Forest plot of hazard ratio (HR) for the impact of cfDNA concentration on PFS. 
complementary roles in predicting treatment response and survival of NSCLC patients. Many studies have investigated the usefulness of cfDNA as a screening tool for NSCLC. However, the predictive or prognostic role of cfDNA remains to be confirmed. In this study, we provided the evidence that high levels of cfDNA were significantly associated with poor survival in NSCLC. In addition, our study indicated that cfDNA could act as a promising predictive factor for response to EGFR-TKIs in NSCLC patients.

To the best of our knowledge, this is the first comprehensive meta-analysis to confirm the prognostic role of cfDNA concentration in NSCLC. Our study suggested that NSCLC patients with higher levels of cfDNA tend to have shorter PFS and OS time. One explanation for our results might be that total cfDNA was able to reflect the underlying tumor burden. Many studies had indicated that tumor cell lysate is the main source of the DNA found in plasma or serum [12]. Besides, the amount of cfDNA in the blood was significantly higher in NSCLC patients than that in healthy controls [9, 48]. What's more, cfDNA levels were associated with tumor volume, tumor stage, lymph node involvement and tumor responses [13]. Newman et al. found that levels of cfDNA

A

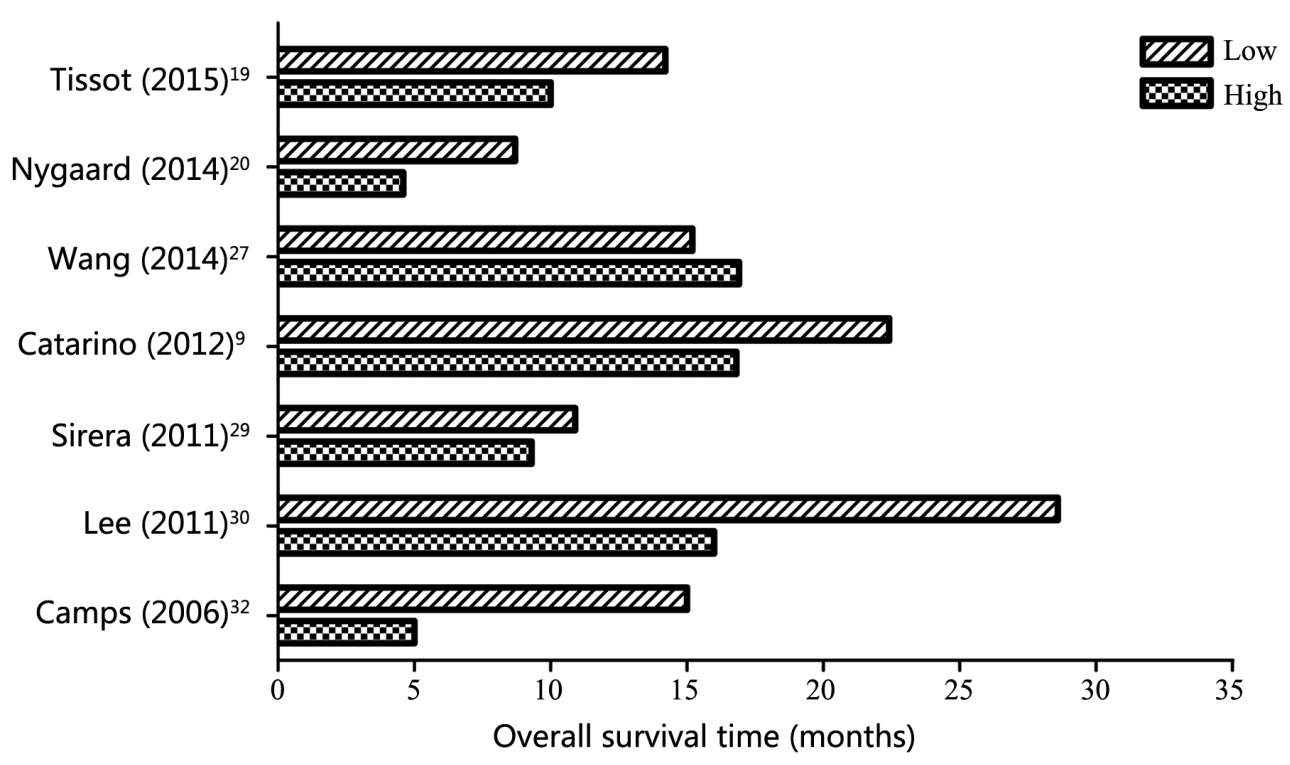

B

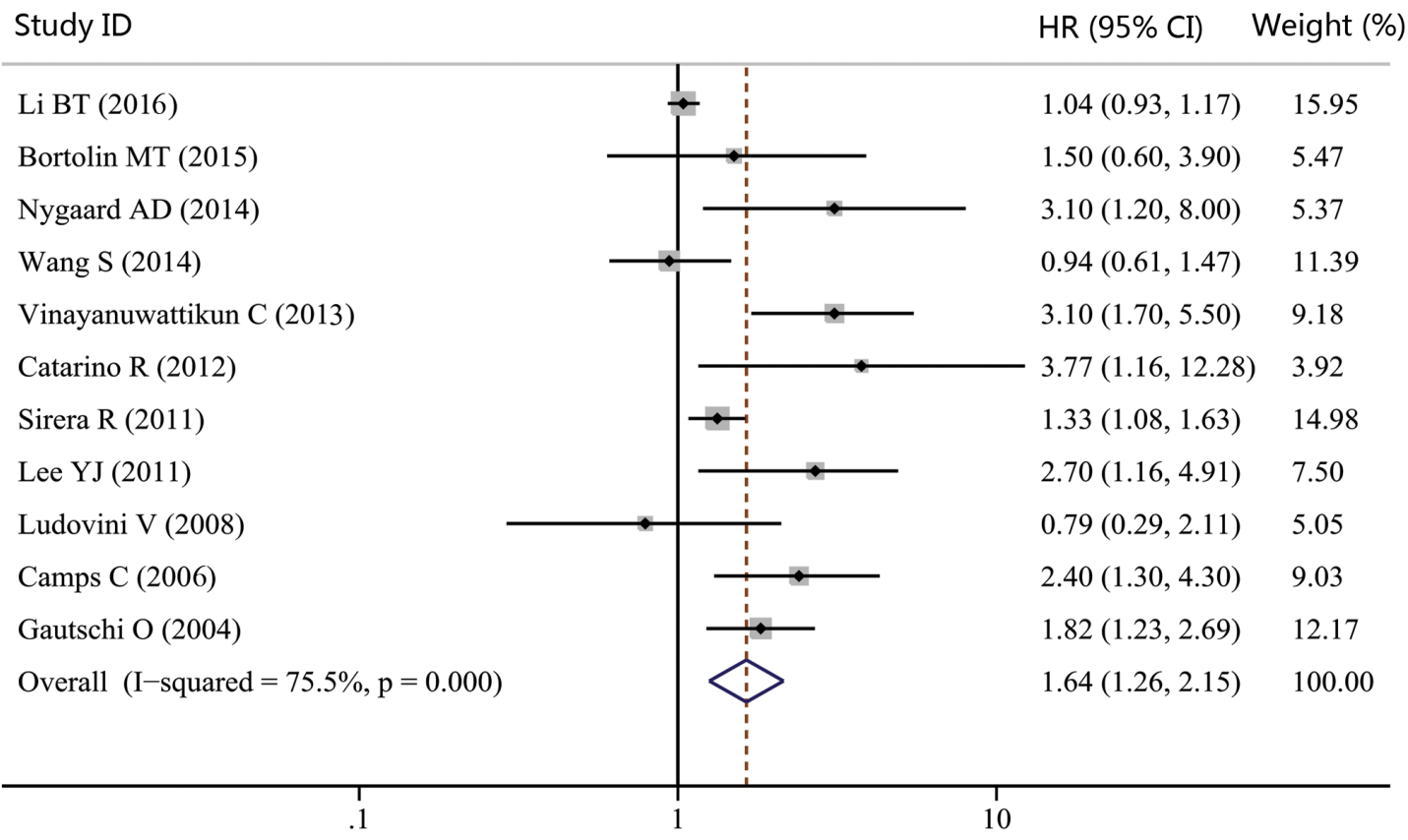

Figure 3: Overall survival (OS) according to cfDNA concentration in NSCLC patients. A. Median OS time according to cfDNA concentration. B. Forest plot of hazard ratio (HR) for the impact of cfDNA concentration on OS. 
significantly correlated with tumor volume and provided earlier response assessment than radiographic approaches [49]. Thus, patients with higher tumor load might have more intensive cfDNA released to the blood and cfDNA levels could reflect the tumor burden. On the other hand, cfDNA levels can be regulated by treatment-caused cell death. In NSCLC patients, an obvious transient rise in cfDNA concentrations occurred immediately after treatment and then it was followed by a rapid decrease [50]. It suggested that cell death caused by treatment could release cfDNA, which decreased as the tumor regressed. These observations revealed that cfDNA levels in plasma or serum were able to reflect the tumor load. Thus, cfDNA can be a surrogate for tumor burden, making it become a valuable prognostic factor for patients with NSCLC.

Targeted therapy based on molecular characterizations has greatly influenced the treatment strategies in NSCLC. Gene mutation analyses are the commonly used predictive biomarkers for selecting NSCLC patients to receive targeted agents. However, the current mutation analyses are often based on tumor tissues and have many limitations. First, the accessibility of tumor tissues is not always satisfactory as most NSCLC patients are diagnosed with advanced stages and

A

\begin{tabular}{|c|c|c|}
\hline Study ID & $\mathrm{HR}(95 \% \mathrm{CI})$ & Weight (\%) \\
\hline Li BT (2016) & $1.06(0.93,1.20)$ & 25.91 \\
\hline Nygaard AD (2014) & $2.00(1.00,4.30)$ & 7.82 \\
\hline Wang S (2014) & $0.79(0.53,1.16)$ & 16.04 \\
\hline Lee YJ (2011) & $1.48(0.96,2.29)$ & 14.60 \\
\hline Sirera R (2011) & $1.44(1.18,1.75)$ & 23.53 \\
\hline Camps C (2006) & $2.00(1.20,3.40)$ & 12.09 \\
\hline Overall $(\mathrm{I}-$ squared $=71.7 \%, \mathrm{p}=0.003)$ & $1.29(1.02,1.65)$ & 100.00 \\
\hline
\end{tabular}

B Study ID HR (95\% CI) Weight (\%)

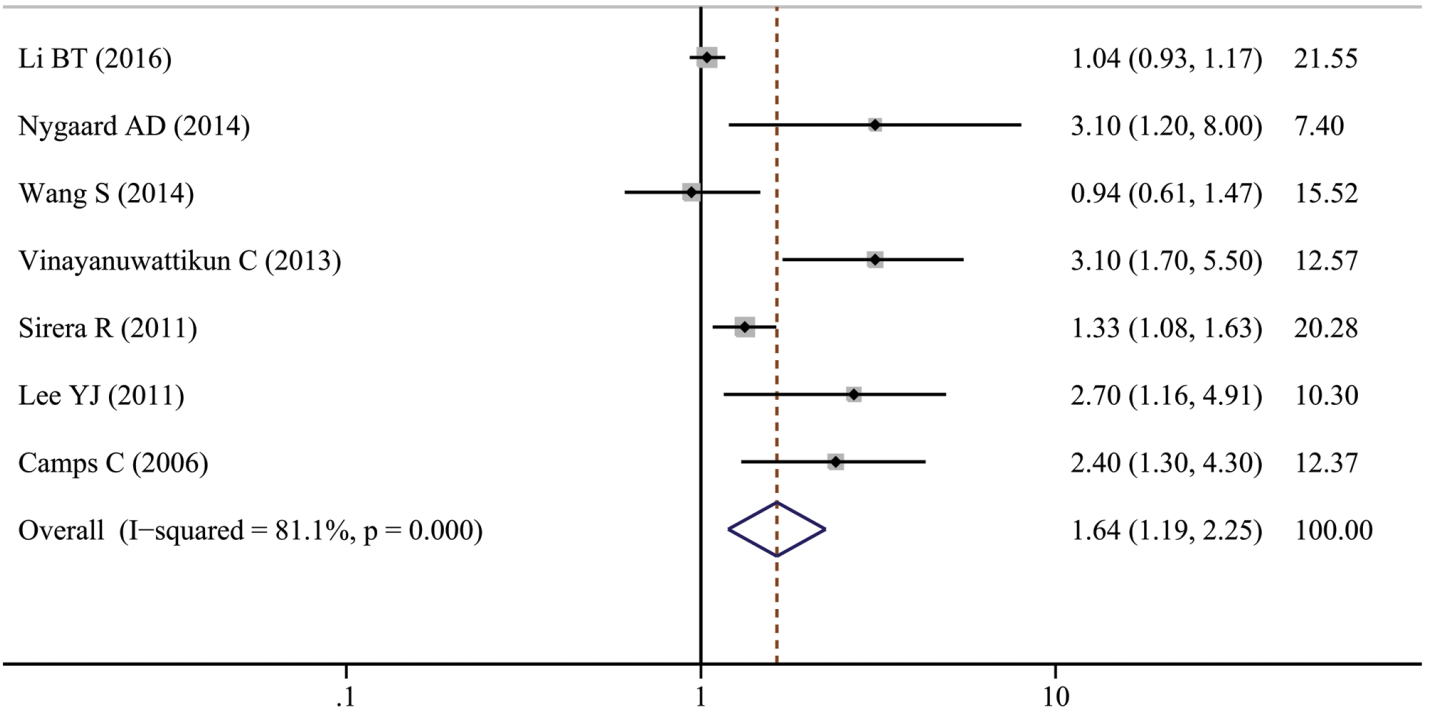

Figure 4: Forest plot of hazard ratio (HR) for the impact of cfDNA concentration on progression-free survival (PFS) and overall survival (OS) in NSCLC patients with advanced stages. A. The impact of cfDNA concentration on PFS. B. The impact of cfDNA concentration on OS. 
unsuitable to provide tissues through invasive surgery or biopsy. Second, surgery and biopsy are not without clinical complications. The adverse events rate for thoracic biopsy was reported to be approximately $20 \%$ [51]. Furthermore, some percentages of NSCLC patients will develop resistance to molecular-targeted agents $[52,53]$. Assessing treatment resistance in real time by repeated surgery or biopsy is not feasible. Considering these limitations, exploring convenient and less invasive techniques to monitor the therapeutic response and effects in NSCLC is urgently needed. Due to its nature of minimal invasiveness, cfDNA is a promising source for gene mutation analyses. In this study, we analyzed the impact of $K R A S$ and $E G F R$ genotype presented in cfDNA on the survival and response to EGFR-TKIs in NSCLC patients. Approximately $15-25 \%$ of patients with NSCLC have KRAS mutations, resulting in constitutive activation of KRAS signaling pathways. Many studies reported that $K R A S$ mutation could predict the poor outcomes of EGFRTKIs treatment and chemotherapy, but several studies argued that KRAS mutation was not associated with the outcome of NSCLC patients [54]. A meta-analysis aimed to clarify the prognostic and predictive value of $K R A S$ mutation in NSCLC was carried out recently [54]. Its

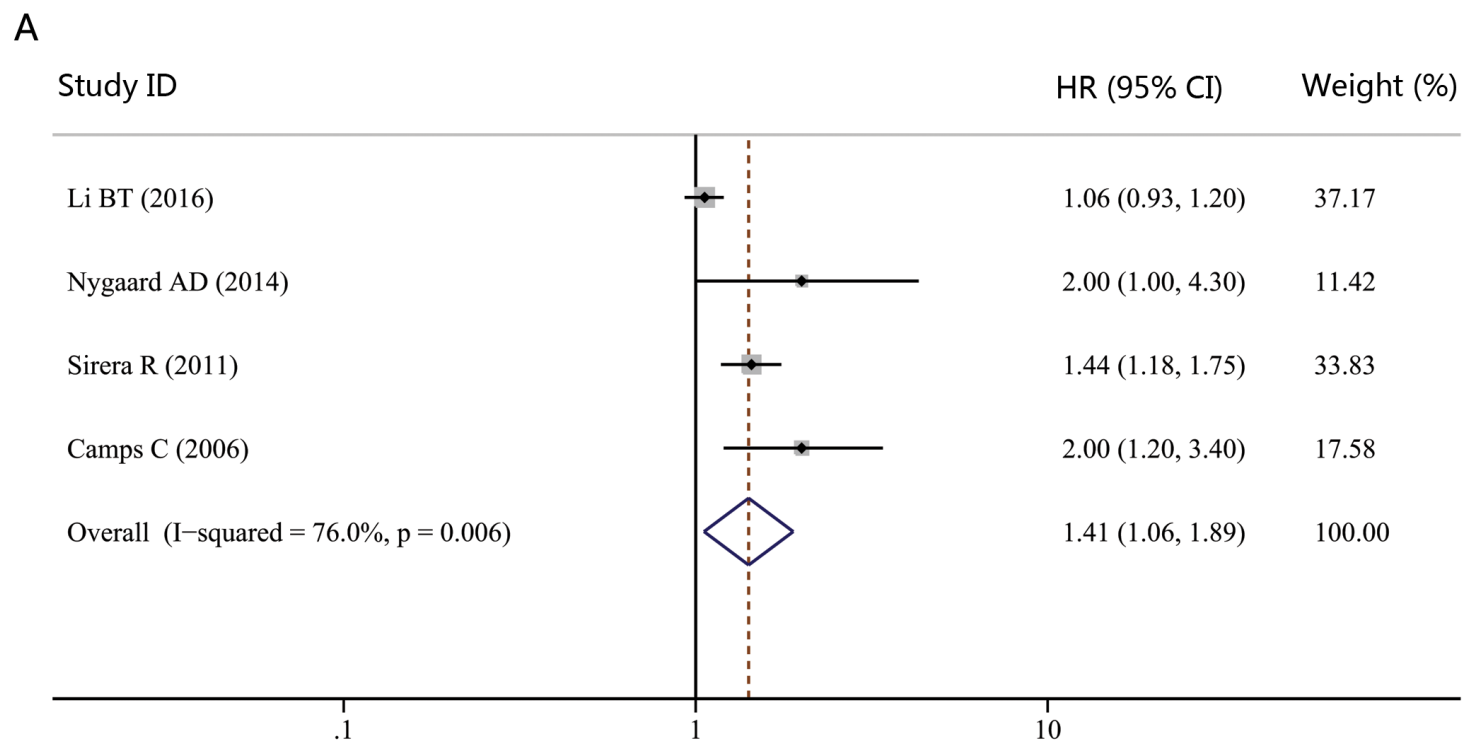

B

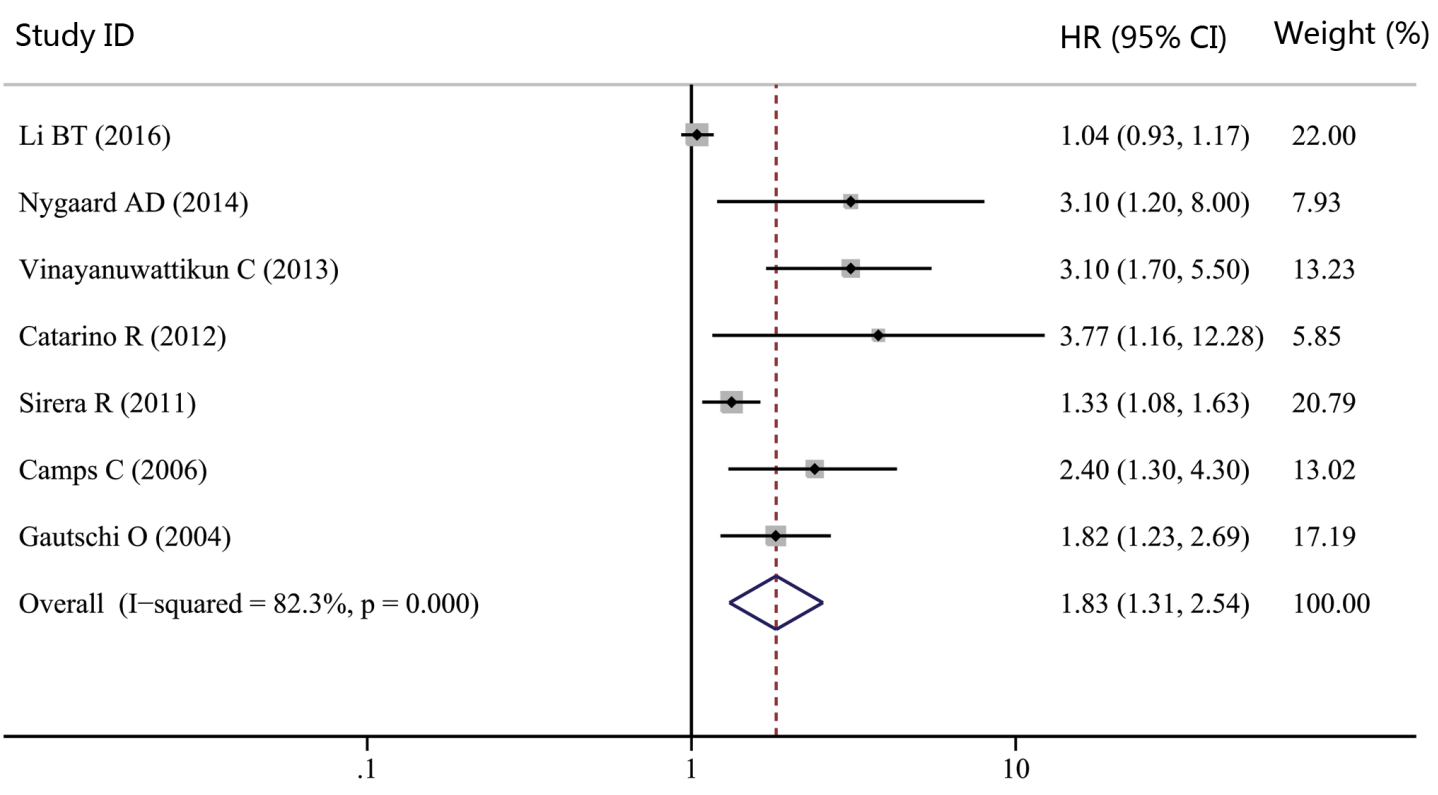

Figure 5: Forest plot of hazard ratio (HR) for the impact of cfDNA concentration on progression-free survival (PFS) and overall survival (OS) in NSCLC patients treated with chemotherapy. A. The impact of cfDNA concentration on PFS. B. The impact of cfDNA concentration on OS. 
results showed that $K R A S$ mutation was significantly associated with worse OS and disease-free survival (DFS) in early stage NSCLC, and with inferior outcomes of EGFR-TKIs treatment and chemotherapy. However, statistical differences in DFS and PFS of chemotherapy and response rates to EGFR-TKIs or chemotherapy were not met when EGFR mutant patients were excluded. Our results indicated that KRAS mutations detected in cfDNA might not be a prognostic factor for the survival of NSCLC patients. One explanation might be that mutations of $K R A S$ and $E G F R$ were generally mutually exclusive in NSCLC $[55,56]$. Most EGFR mutations were existed in $K R A S$ wild-type patients, which might bias the results toward an overestimation of the prognostic and predictive value of $K R A S$ mutation. Another reason might be that the amount of studies which assessed the prognostic value of $K R A S$ mutation presented in cfDNA in NSCLC was small. Thus, the clinical significance of $K R A S$ mutation detected in cfDNA is yet under debate. Future large-scaled trails are still needed to improve our results.

Nowadays, EGFR-TKIs are the most successful example of targeted therapy in NSCLC. EGFR gene mutations are the standard biomarkers for selecting NSCLC patients to receive EGFR-TKIs treatment. As a high degree of correlation between EGFR mutations detected in tumors and those presented in cfDNA has been confirmed by two recent meta-analyses [17, 18], $E G F R$ mutation presented in cfDNA may also be useful predictive markers for guiding NSCLC patients to receive EGFR-TKIs. Indeed, several studies have analyzed the association between cfDNA EGFR mutation status and clinical outcomes. Goto et al. [44] found a significant correlation between cfDNA EGFR mutation status and PFS. In cfDNA EGFR activating mutation subgroup, NSCLC patients had longer PFS when they were treated with gefitinib. Another research demonstrated that EGFR

A

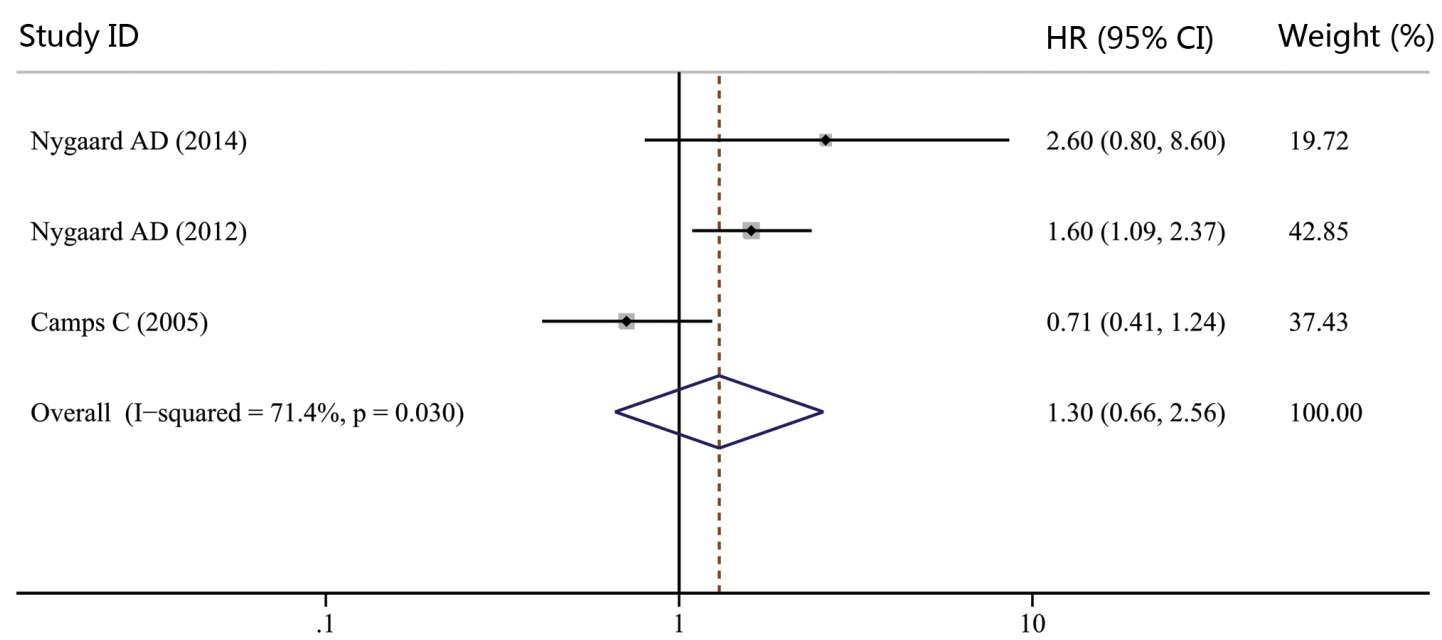

B

\begin{tabular}{|c|c|c|}
\hline Study ID & HR $(95 \%$ CI) & Weight (\%) \\
\hline Nygaard AD (2014) & $2.50(0.70,8.60)$ & 17.12 \\
\hline Nygaard AD (2012) & $1.87(1.23,2.84)$ & 29.23 \\
\hline Gautschi O (2007) & $0.46(0.25,0.86)$ & 26.47 \\
\hline Camps C (2005) & $0.74(0.41,1.28)$ & 27.18 \\
\hline Overall $(\mathrm{I}-\mathrm{squared}=82.7 \%, \mathrm{p}=0.001)$ & $1.05(0.49,2.25)$ & 100.00 \\
\hline .1 & & \\
\hline
\end{tabular}

Figure 6: Forest plot of hazard ratio (HR) for the impact of $K R A S$ genotype detected in cfDNA on progression-free survival (PFS) and overall survival (OS). A. The impact of $K R A S$ genotype detected in cfDNA on PFS. B. The impact of $K R A S$ genotype detected in cfDNA on OS. 
mutation status in cfDNA was a good predictor for PFS after EGFR-TKIs treatment [57]. Consistently, our results showed that $E G F R$ activating mutation in cfDNA indicated a greater chance of response to EGFR-TKIs in NSCLC patients. Thus, cfDNA EGFR mutation test had a good ability to predict the efficacy of EGFR-TKIs treatment. cfDNA might be a reliable material to guide EGFR-TKIs treatment for NSCLC patients.
However, there were some limitations in our present meta-analysis. Firstly, our analyses were based on the literature, making our results less reliable than individual patient data-based analysis. Secondly, a significant heterogeneity was presented in this study. When subgroup analyses were performed in terms of clinical stages and therapeutic regimens, the heterogeneity between studies did not change obviously. The heterogeneity might partly

Study ID

OR $(95 \%$ CI $\quad$ Weight (\%)

\begin{tabular}{|c|c|c|c|}
\hline Bai H (2009) & $\rightarrow$ & $2.58(1.54,4.32)$ & 19.00 \\
\hline Douillard JY (2014) & & $1.29(0.96,1.74)$ & 48.94 \\
\hline $\mathrm{He} \mathrm{C}(2009)$ & $\rightarrow-$ & $3.55(1.26,9.94)$ & 4.80 \\
\hline Kimura H (2007) & & $7.50(2.84,19.80)$ & 2.33 \\
\hline Kimura H (2006) & & $1.36(0.47,3.92)$ & 6.46 \\
\hline Kim ST (2013) & & $6.80(1.72,26.86)$ & 1.59 \\
\hline Li XF (2014) & $\rightarrow$ & $1.76(1.06,2.93)$ & 16.88 \\
\hline Overall $(\mathrm{I}-$ squared $=71.4 \%, \mathrm{p}=0.002)$ & & $1.96(1.59,2.42)$ & 100.00 \\
\hline
\end{tabular}

Figure 7: Forest plot of odds ratio (OR) for the impact of EGFR genotype detected in cfDNA on response to EGFRTKIs.

A

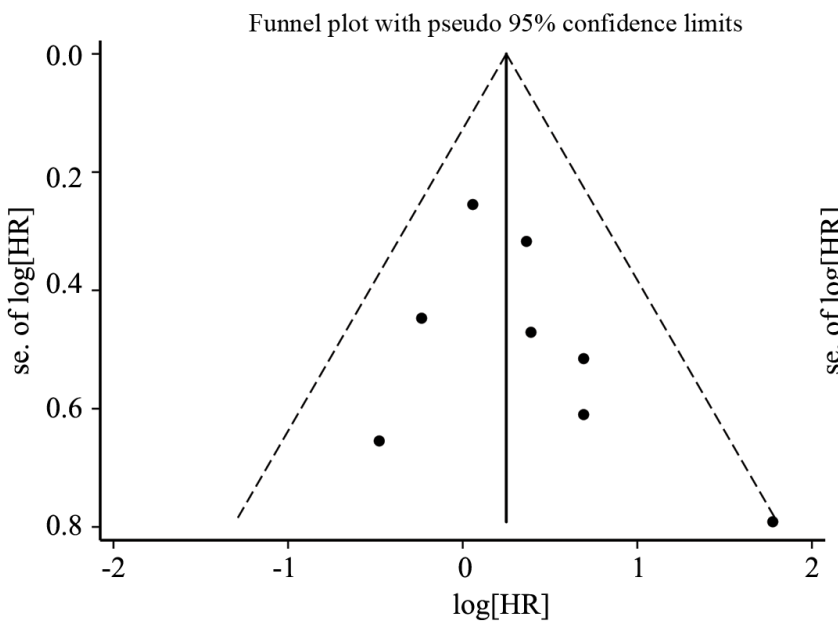

B

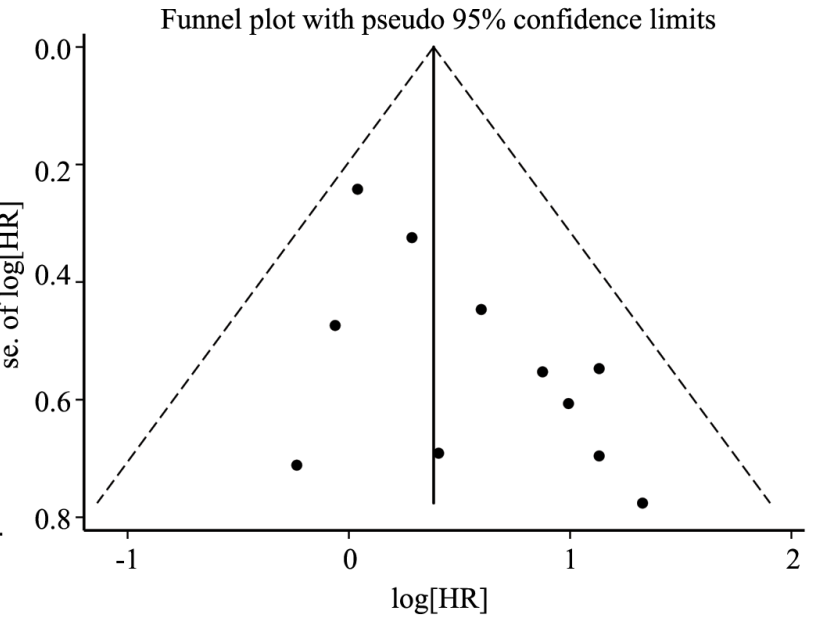

Figure 8: Funnel plot for the assessment of publication bias in this study. A. Funnel plot for 8 studies reporting progression-free survival (PFS). B. Funnel plot for 11 studies reporting overall survival (OS). 
come from other variations, such as techniques that were adopted to detect cfDNA. Future standardization of cfDNA assessment would hopefully solve this problem. Thirdly, studies that could not provide sufficient data for extracting OR or HR were excluded. The exclusion of these studies might make the pooled estimates differ from their true value on some level.

In view of this study, our findings suggested that cfDNA could act as a predictive and prognostic biomarker for patients with NSCLC. High levels of cfDNA were significantly associated with poor PFS and OS in NSCLC. In addition, EGFR activating mutation status in cfDNA indicated a greater chance of response to EGFR-TKIs. In conclusion, cfDNA had a prognostic and predictive value for NSCLC patients, which might help to define high risk patients and guide clinical decision making. However, considering the limitations of a literature-based metaanalysis, these results need to be validated and updated by future large-scaled researches.

\section{MATERIALS AND METHODS}

\section{Literature searches}

Electronic searches for relevant articles in PubMed, Embase, and Web of Science databases were conducted in January 2016. The search strategy was generated by combining key words related to cfDNA ('circulating cell-free DNA' or 'plasma cell-free DNA' or 'serum cellfree DNA') and NSCLC ('non small cell lung cancer' or 'NSCLC'). Moreover, we manually searched the reference lists of relevant articles for additional publications.

\section{Inclusion criteria}

Studies were included in this meta-analysis if they met the following criteria: (1) all patients recruited in the study were diagnosed with NSCLC; (2) the predictive or prognostic value of cfDNA was evaluated; (3) only English-language studies were included; (4) the HR or OR and their corresponding 95\% CIs were described or could be statistically extracted; (5) When several studies reported the same patient population, the newest or most informative study was included.

\section{Data extraction}

Data extraction was performed independently by 2 reviewers and disagreements among them were resolved by consensus. The following information was extracted from each study: first author's name, publication year, country of origin, number of patients, therapeutic regimen, cfDNA assessment (methods), cfDNA analysis (quantification and molecular characterization) and clinical factors (PFS, OS and ORR).

\section{Statistical analysis}

HR and its 95\% CIs were used to estimate the prognostic value of cfDNA. OR and its 95\% CIs were adopted to describe the correlation between cfDNA status and objective response rates. The individual HR or OR estimates were combined into an overall HR or OR, and the results were presented in the form of a forest plot. Pooled effect sizes were considered to be significantly different if their 95\% CIs did not include $1(\mathrm{p}<0.05)$. $\mathrm{HR}>1$ implied a poor survival and OR $>1$ indicated a greater chance of objective response. Median pooled PFS and OS were summarized using descriptive statistics. The heterogeneity between studies was assessed by the Cochran Q test and $I^{2}$ test. When Cochran Q test $\mathrm{P}$ value was $\leq 0.10$ and $I^{2}$ test $I^{2}$ value was $\geq 50 \%$, statistically significant heterogeneity was considered to be present. Fixed effects models were employed when heterogeneity was absent; otherwise, random effects models were adopted. Funnel plots, Begg's test, and Egger's test were performed to detect publication bias. All analyses were carried out by using Stata Statistical Software, version 12.0 (Stata Corporation, College Station, TX, USA).

\section{CONFLICTS OF INTEREST}

The authors declared no conflicts of interest.

\section{REFERENCES}

1. Torre LA, Bray F, Siegel RL, et al. Global cancer statistics, 2012. CA Cancer J Clin. 2015; 65:87-108.

2. Howlader N, Noone AM, Krapcho M, et al. SEER Cancer Statistics Review, 1975-2012, National Cancer Institute. Bethesda, MD, http://seer.cancer.gov/csr/1975_2012/, based on November 2014 SEER data submission, posted to the SEER web site, April 2015.

3. De Mattos-Arruda L, Caldas C. Cell-free circulating tumour DNA as a liquid biopsy in breast cancer. Mol Oncol. 2015. doi: 10.1016/j.molonc.2015.12.001. [Epub ahead of print].

4. Gray ES, Rizos H, Reid AL et al. Circulating tumor DNA to monitor treatment response and detect acquired resistance in patients with metastatic melanoma. Oncotarget. 2015; 6:42008-42018. doi: 10.18632/oncotarget.5788.

5. Carpinetti P, Donnard E, Bettoni F et al. The use of personalized biomarkers and liquid biopsies to monitor treatment response and disease recurrence in locally advanced rectal cancer after neoadjuvant chemoradiation. Oncotarget. 2015; 6:38360-38371. doi: 10.18632/oncotarget.5256.

6. Jiang T, Ren S, Zhou C. Role of circulating-tumor DNA analysis in non-small cell lung cancer. Lung Cancer. 2015; 90:128-134.

7. Xia S, Kohli M, Du M et al. Plasma genetic and genomic abnormalities predict treatment response and clinical 
outcome in advanced prostate cancer. Oncotarget. 2015; 6:16411-16421. doi: 10.18632/oncotarget.3845.

8. Stroun M, Maurice P, Vasioukhin V et al. The origin and mechanism of circulating DNA. Ann N Y Acad Sci. 2000; 906:161-168.

9. Catarino R, Coelho A, Araujo A et al. Circulating DNA: diagnostic tool and predictive marker for overall survival of NSCLC patients. PLoS One. 2012; 7:e38559.

10. Szpechcinski A, Chorostowska-Wynimko J, Struniawski R et al. Cell-free DNA levels in plasma of patients with nonsmall-cell lung cancer and inflammatory lung disease. Br J Cancer. 2015; 113:476-483

11. Szpechcinski A, Rudzinski P, Kupis W et al. Plasma cell-free DNA levels and integrity in patients with chest radiological findings: NSCLC versus benign lung nodules. Cancer Lett. 2016. doi: 10.1016/j.canlet.2016.02.002. [Epub ahead of print].

12. Zhang R, Shao F, Wu X et al. Value of quantitative analysis of circulating cell free DNA as a screening tool for lung cancer: a meta-analysis. Lung Cancer. 2010; 69:225-31.

13. Nie K, Jia Y, Zhang X. Cell-free circulating tumor DNA in plasma/serum of non-small cell lung cancer. Tumour Biol. 2015; 36:7-19.

14. Zhao X, Han RB, Zhao J et al. Comparison of epidermal growth factor receptor mutation statuses in tissue and plasma in stage I-IV non-small cell lung cancer patients. Respiration. 2013; 85:119-125.

15. Ishii H, Azuma K, Sakai K et al. Digital PCR analysis of plasma cell-free DNA for non-invasive detection of drug resistance mechanisms in EGFR mutant NSCLC: Correlation with paired tumor samples. Oncotarget. 2015; 6:30850-30858. doi: 10.18632/oncotarget.5068.

16. Bai H, Mao L, Wang HS et al. Epidermal growth factor receptor mutations in plasma DNA samples predict tumor response in Chinese patients with stages IIIB to IV nonsmall-cell lung cancer. J Clin Oncol. 2009; 27:2653-2659.

17. Qiu M, Wang J, Xu Y et al. Circulating tumor DNA is effective for the detection of EGFR mutation in nonsmall cell lung cancer: a meta-analysis. Cancer Epidemiol Biomarkers Prev. 2015; 24:206-212.

18. Luo J, Shen L, Zheng D. Diagnostic value of circulating free DNA for the detection of EGFR mutation status in NSCLC: a systematic review and meta-analysis. Sci Rep. 2014; 4:6269.

19. Tissot C, Toffart AC, Villar S et al. Circulating free DNA concentration is an independent prognostic biomarker in lung cancer. Eur Respir J. 2015; 46:1773-1780.

20. Dowler Nygaard A, Spindler KL, Pallisgaard N et al. Levels of cell-free DNA and plasma KRAS during treatment of advanced NSCLC. Oncol Rep. 2014; 31:969-974.

21. Bortolin MT, Tedeschi R, Bidoli E et al. Cell-free DNA as a prognostic marker in stage I non-small-cell lung cancer patients undergoing stereotactic body radiotherapy. Biomarkers. 2015; 20:422-428.
22. Li BT, Drilon A, Johnson ML et al. A prospective study of total plasma cell-free DNA as a predictive biomarker for response to systemic therapy in patients with advanced non-small-cell lung cancersdagger. Ann Oncol. 2016; 27:154-159.

23. Nygaard AD, Garm Spindler KL, Pallisgaard $N$ et al. The prognostic value of KRAS mutated plasma DNA in advanced non-small cell lung cancer. Lung Cancer. 2013; 79:312-317.

24. Kimura H, Suminoe M, Kasahara K et al. Evaluation of epidermal growth factor receptor mutation status in serum DNA as a predictor of response to gefitinib (IRESSA). Br J Cancer. 2007; 97:778-784.

25. Camps $\mathrm{C}$, Sirera $\mathrm{R}$, Bremnes $\mathrm{R}$ et al. Is there a prognostic role of K-ras point mutations in the serum of patients with advanced non-small cell lung cancer? Lung Cancer. 2005; 50:339-346.

26. Douillard JY, Ostoros G, Cobo M et al. Gefitinib treatment in EGFR mutated caucasian NSCLC: circulating-free tumor DNA as a surrogate for determination of EGFR status. J Thorac Oncol. 2014; 9:1345-1353.

27. Wang $\mathrm{S}$, Han $\mathrm{X}, \mathrm{Hu} \mathrm{X}$ et al. Clinical significance of pretreatment plasma biomarkers in advanced non-small cell lung cancer patients. Clin Chim Acta. 2014; 430:63-70.

28. Vinayanuwattikun $\mathrm{C}$, Winayanuwattikun $\mathrm{P}$, Chantranuwat $\mathrm{P}$ et al. The impact of non-tumor-derived circulating nucleic acids implicates the prognosis of non-small cell lung cancer. J Cancer Res Clin Oncol. 2013; 139:67-76.

29. Sirera R, Bremnes RM, Cabrera A et al. Circulating DNA is a useful prognostic factor in patients with advanced nonsmall cell lung cancer. J Thorac Oncol. 2011; 6:286-290.

30. Lee YJ, Yoon KA, Han JY et al. Circulating cellfree DNA in plasma of never smokers with advanced lung adenocarcinoma receiving gefitinib or standard chemotherapy as first-line therapy. Clin Cancer Res. 2011; 17:5179-5187.

31. Ludovini V, Pistola L, Gregorc V et al. Plasma DNA, microsatellite alterations, and p53 tumor mutations are associated with disease-free survival in radically resected non-small cell lung cancer patients: a study of the perugia multidisciplinary team for thoracic oncology. $\mathrm{J}$ Thorac Oncol. 2008; 3:365-373.

32. Camps C, Sirera R, Bremnes RM et al. Quantification in the serum of the catalytic fraction of reverse telomerase: a useful prognostic factor in advanced non-small cell lung cancer. Anticancer Res. 2006; 26:4905-4909.

33. Gautschi O, Bigosch C, Huegli B et al. Circulating deoxyribonucleic Acid as prognostic marker in non-smallcell lung cancer patients undergoing chemotherapy. J Clin Oncol. 2004; 22:4157-4164.

34. Gautschi O, Huegli B, Ziegler A et al. Origin and prognostic value of circulating KRAS mutations in lung cancer patients. Cancer Lett. 2007; 254:265-273. 
35. He C, Liu M, Zhou C et al. Detection of epidermal growth factor receptor mutations in plasma by mutant-enriched PCR assay for prediction of the response to gefitinib in patients with non-small-cell lung cancer. Int J Cancer. 2009; 125:2393-2399.

36. Kimura H, Kasahara K, Kawaishi M et al. Detection of epidermal growth factor receptor mutations in serum as a predictor of the response to gefitinib in patients with non-small-cell lung cancer. Clin Cancer Res. 2006; 12:3915-3921.

37. Kim ST, Sung JS, Jo UH et al. Can mutations of EGFR and KRAS in serum be predictive and prognostic markers in patients with advanced non-small cell lung cancer (NSCLC)? Med Oncol. 2013; 30:328.

38. Li X, Ren R, Ren S et al. Peripheral blood for epidermal growth factor receptor mutation detection in non-small cell lung cancer patients. Transl Oncol. 2014; 7:341-8.

39. Camps C, Jantus-Lewintre E, Cabrera A et al. The identification of KRAS mutations at codon 12 in plasma DNA is not a prognostic factor in advanced non-small cell lung cancer patients. Lung Cancer. 2011; 72:365-369.

40. Karachaliou N, Mayo-de las Casas C, Queralt C et al. Association of EGFR L858R Mutation in Circulating Free DNA With Survival in the EURTAC Trial. JAMA Oncol. 2015; 1:149-157.

41. Wang Z, Chen R, Wang S et al. Quantification and dynamic monitoring of EGFR T790M in plasma cell-free DNA by digital PCR for prognosis of EGFR-TKI treatment in advanced NSCLC. PLoS One. 2014; 9:e110780.

42. Punnoose EA, Atwal S, Liu W et al. Evaluation of circulating tumor cells and circulating tumor DNA in nonsmall cell lung cancer: association with clinical endpoints in a phase II clinical trial of pertuzumab and erlotinib. Clin Cancer Res. 2012; 18:2391-2401.

43. Zhuo ML, Wu MN, Zhao J et al. Epidermal growth factor receptor genotype in plasma DNA and outcome of chemotherapy in the Chinese patients with advanced non-small cell lung cancer. Chin Med J (Engl). 2011; 124:3510-3514.

44. Goto K, Ichinose Y, Ohe Y et al. Epidermal growth factor receptor mutation status in circulating free DNA in serum: from IPASS, a phase III study of gefitinib or carboplatin/ paclitaxel in non-small cell lung cancer. J Thorac Oncol. 2012; 7:115-121.

45. Thress KS, Brant R, Carr TH et al. EGFR mutation detection in ctDNA from NSCLC patient plasma: A cross-platform comparison of leading technologies to support the clinical development of AZD9291. Lung Cancer. 2015; 90:509-515.

46. Nygaard AD, Holdgaard PC, Spindler KL et al. The correlation between cell-free DNA and tumour burden was estimated by PET/CT in patients with advanced NSCLC. Br J Cancer. 2014; 110:363-368.

47. Sun W, Yuan X, Tian Y et al. Non-invasive approaches to monitor EGFR-TKI treatment in non-small-cell lung cancer. J Hematol Oncol. 2015; 8:95.

48. Ulivi P, Mercatali L, Casoni GL et al. Multiple marker detection in peripheral blood for NSCLC diagnosis. PLoS One. 2013; 8:e57401.

49. Newman AM, Bratman SV, To J et al. An ultrasensitive method for quantitating circulating tumor DNA with broad patient coverage. Nat Med. 2014; 20:548-554.

50. Szpechcinski A, Chorostowska-Wynimko J, Kupis W et al. Quantitative analysis of free-circulating DNA in plasma of patients with resectable NSCLC. Expert Opin Biol Ther. 2012; 12:S3-9.

51. Overman MJ, Modak J, Kopetz S et al. Use of research biopsies in clinical trials: are risks and benefits adequately discussed? J Clin Oncol. 2013; 31:17-22.

52. Janne PA. Challenges of detecting EGFR T790M in gefitinib/erlotinib-resistant tumours. Lung Cancer. 2008; 60:S3-9.

53. Russo A, Franchina T, Ricciardi GR et al. A decade of EGFR inhibition in EGFR-mutated non small cell lung cancer (NSCLC): Old successes and future perspectives. Oncotarget. 2015; 6:26814-26825. doi: 10.18632/oncotarget.4254.

54. Pan W, Yang Y, Zhu H et al. KRAS mutation is a weak, but valid predictor for poor prognosis and treatment outcomes in NSCLC: A meta-analysis of 41 studies. Oncotarget. 2016;7:8373-88. doi: 10.18632/oncotarget.7080.

55. Dogan S, Shen R, Ang DC et al. Molecular epidemiology of EGFR and KRAS mutations in 3,026 lung adenocarcinomas: higher susceptibility of women to smoking-related KRAS-mutant cancers. Clin Cancer Res. 2012; 18:6169-6177.

56. Boch C, Kollmeier J, Roth A et al. The frequency of EGFR and KRAS mutations in non-small cell lung cancer (NSCLC): routine screening data for central Europe from a cohort study. BMJ Open. 2013; 3:e02560.

57. Weber B, Meldgaard P, Hager $\mathrm{H}$ et al. Detection of EGFR mutations in plasma and biopsies from non-small cell lung cancer patients by allele-specific PCR assays. BMC Cancer. 2014; 14:294. 